\title{
C.:SE
}

\section{Primary Hyperparathyroidism Caused by Single Parathyroid Adenoma}

\author{
Jose RL Batubara, Paruhum T Siregar, M Lutfi, Daniel Makes, Wawan Hermawan
}

(Departments of Child Health and Radiology, MedicalSchool, University of Indonesia, Jakarta)

\begin{abstract}
Primary hyperparathyroidism is rarely found in children under sixteen years old. We report the first case seen at the Department of Child Health, Medical School, University of Indonesia, Jakarta. This 15-year old girl was admitted to the Department, referred by an orthopedic surgeon because of pathologic fractures suspected to be caused by hyperparathyroidism. The physical examination was unremarkable, and the laboratory findings showed increased level of parathyroid hormone. Roentgenologic examination showed lytic skull lesions, loss of the lamina dura of the dentis, subperiosteal resorption of the symphysis and generalized osteoporosis with pathologic fractures. Color Doppler USG using a high resolution ultrasound examination was performed to find the etiology of primary hy perparathyroidism. The result revealed single parathyroid adenoma in the right superior region measuring $2.7 \times 1.7 \times 1 \mathrm{~cm}$. The clinical manifestations and laboratory findings showed improvement following surgery. [Paediatr Indones 1995;35:236-240]
\end{abstract}

\section{Introduction}

Primary hyperparathyroidism is generally a disease of adults rather than in children; especially in children under sixteen years old this is a rare case. ${ }^{1,2}$ Single parathyroid adenoma is the most common etiology of primary hyperparathyro-

Accepted for publication: July 27,1995. Author's address: Jose RL Batubara, MD. Department of Child Health, Medical School, University of Indonesia, Jakarta 10430. Tel (62) (21) 390-7742; Fax 390-7743 dism, i.e., in about $80 \%$ or more of cases. Sometimes we can find multiple parathyroid adenoma. The other causes are primary hyperplasia of parathyroid glands and parathyroid carcinoma. ${ }^{3}$

The purpose of this report is to describe a child seen at the Department of Child Health, Cipto Mangunkusumo Hospital who had primary hyperparathyroidism due to a single parathyroid adenoma. This was the first case diagnosed at the 
Department of Child Health, Medical School, University of Indonesia / Cipto Mangunkusumo Hospital, Jakarta.

\section{Report of the Case}

A 15-year old girl was hospitalized for the first time at the Department of Child Health, Cipto Mangunkusumo Hospital from March 27, until April 5, 1995. She was referred by an orthopedic surgeon with pathologic fractures suspected as caused by hyperparathyroidism. History of illness disclosed that about 3 years prior to admission she fell down in the sitting position and broke her left leg. Her parents took her to an orthopedic surgeon and she underwent operation for the first time. Three months after surgery when trying to walk, she fell down again and broke the same leg. She was taken to a Chinese traditional healer who managed her for about six months. Since there was no improvement, her parents took her to the orthopedic surgeon again who performed a second operation. Result of $\mathrm{x}$-rays (bone survey) showed that there was generalized osteoporosis apparently associated with hyperparathyroidism. The surgeon referred her to a pediatrician in a Child and Maternity Hospital; however, after about 1 year of investigation there was no definite diagnosis, since the laboratory findings always within normal limits. Because there was no improvement, she went back to the orthopedic surgeon and then she was referred to Endocrinology Division, Department of Child Health, Cipto Mangunkusumo Hospital. During the illness there were no complain of nausea, vomit- ing, abdominal discomfort, constipation, confusion, delusions, hallucinations, impaired memory, lack of interest and initiative, depression or varying levels of consciousness.

Physical examination revealed a female with body weight of $37 \mathrm{~kg}$ and height of $143 \mathrm{~cm}$. Pulse rate 84 per minute, respiratory rate 24 per minute, body temperature $36.2^{\circ} \mathrm{C}$, blood pressure $110 / 70$ $\mathrm{mmHg}$. There were no abnormalities in eyes and ENT. No neck masses were palpated. Heart, lungs and abdomen were within normal limits. There was hipotrophy of the lower extremities and vague bone pains.

Laboratory data revealed a parathyroid hormone $789 \mathrm{pg} / \mathrm{ml}$, ionized calcium $1,40 \mathrm{Umol} / \mathrm{L}$, serum calcium $11,7 \mathrm{mg} / \mathrm{dl}$, inorganic phosphate $2,1 \mathrm{mg} / \mathrm{dl}$, sodium $136 \mathrm{mEq} / \mathrm{L}$, potassium 3,9 mEq/L, magnesium $2,3 \mathrm{mg} / \mathrm{dl}$, chloride $100 \mathrm{mEq} / \mathrm{L}$.

Uninary electrolytes for 24 hours showed the followings: sodium $56 \mathrm{mmol}$, potassium $26 \mathrm{mmol}$, inorganic phosphorus $240 \mathrm{mg}$, magnesium $10 \mathrm{mmol}$. Blood ureum $24 \mathrm{mg} / \mathrm{dl}$, creatinine $0.60 \mathrm{mg} / \mathrm{dl}$, ureum clearance test (UCT) 62,69 $\mathrm{ml} /$ minute $/ 1,73 \mathrm{~m}^{2}$, creatinine clearance test (CCT) $61,63 \mathrm{ml} / \mathrm{minute} / 1,73 \mathrm{~m}^{2}$.

Roentgenologic examination showed lytic skull lesions, loss of the lamina dura of the dentis, subperiosteal resorption of the symphysis and generalized osteoporosis. There were also pathologic fractures of one third proximal and medial of left femur. Plain abdominal photo showed no calcification. Ultrasonography of the urinary tracts showed normal features.

Color Doppler USG using a high resolution ultrasound examination was performed to find the etiology of primary hy- 
perparathyroidism. The result revealed single parathyroid adenoma in the right superior region measuring $2.7 \times 1.7 \times 1$ $\mathrm{cm}$.

Before doing surgical removal thyroid scanning was performed and the result showed that iodine uptake of the thyroid glands was homogenous. Thyroid hormone (thyroxin and triiodothyronin) levels and thyroid stimulating hormone (TSH) were within normal limits.

At surgical exploration performed by oncologic surgeon a single adenoma was found at the right superior parathyroid region; this was removed. The post operative course was uneventful. Five days af ter operation the serum calcium fell to subnormal level with the lowest calcium level was $6.2 \mathrm{mg} / \mathrm{dl}$. She had transient tetany, so that oral and intravenous calcium was administered.

On the subsequent follow-up the tetany disappeared. The calcium serum level was $8.6 \mathrm{mg} / \mathrm{dl}$, ionized calcium 1.08 Umol/L, inorganic phosphorus $2.8 \mathrm{mg} /$ $\mathrm{dl}$, and parathyroid hormone was 70.2 $\mathrm{pg} / \mathrm{ml}$.

On the 12th day after operation the patient was discharged in a good condition. At the first visit to Endocrinology Outpatient Clinic the patient still used roller chair, but there was no complain of bone pain, and the hypotrophy of the lower extremities has disappeared.

\section{Discussion}

The incidence of primary hyperparathyroidism in children under sixteen years old still rare. In residents of Rochester, Minn., USA, from 1965 to 1976; 90 cases were found. From January 1, 1965 to June 31, 1974 the average annual incidence was $7.8 \pm 1.2$ cases per 100,000 population. Even after the availability of routine measurement of serum calcium the annual incidence of primary hyperparathyroidism among person 39 years of age or younger remained below 10 cases per $100,000 .^{4}$

In the Department of Child Health, Cipto Mangunkusumo Hospital this is the first case of primary hyperparathyroidism caused by single parathyroid adenoma. As mentioned in the literature, the most common etiology was single parathyroid adenoma, for about $80 \%$ or more. Occasionally multiple adenomas are found. A less common cause is primary "water clear" cell hyperplasia of all four glands $(10 \%$ or less) or primary "chief" cell hyperplasia of all four glands, which is less common ( $8 \%$ or less). Carcinoma of one parathyroid gland is the rarest one $(2 \%){ }^{3}$

Hyperparathyroidism is firstly suspected by orthopedic surgeon because the presence of pathologic fractures and the radiological features show generalized osteoporosis. Unfortunately the first pediatrician who investigated this patient had found nothing because all laboratory findings were always within normal limits.

The symptoms of primary hyperparathyroidism may be divided into those that result from hypercalcemia and those that result from complications of altered me tabolism of calcium and phosphorus. The clinical manifestations of primary hyperparathyroidism are 1. gastrointestinal, 2 . central nervous system, 3 , neuromuscular, 4. bone, and 5, renal. Gastroin- testinal manifestation, primarily related to the degree of hypercalcemia, are nauto the degring, abdominal discomfort, consea, vomiting, abdominal discomfort, Constipation, and system symptoms resulting from hypercalcemia, are delusion, confusion, hallucination, impaired memory, lack of interest and initiative, depression, and varying levels of consciousness. Neuand varying levels of romuscular manifestations, presumably on a neuropathological basis, include weakness, easy fatigability and muscle atrophy, especially the proximal muscles of the limbs, twitching of the tongue re sembling fasciculation, and paresthesis in the extremities.

Osteolytic activity of PTH produces bone symptoms including vague bone pain. Renal changes are polyuria and polydipsia related to the hypercalcemia and increased filtered $\mathrm{Ca}$, renal colic from re nal stones, and hypertension. Hypercalcemia may be diagnosed by careful ophthalmological examination of the cornea scleral junction for corneal calcification. Unfortunately, the disease is commonly unrecognized until symptoms of complication occur. In this patient an excessive production of parathyroid hormone by production of parmalaparathyr of ocolastic activity of the bone and produced bone symptoms and signs including generalized demineralization, pathologic fractures, and vague bone pathologic since hypercalcemia was mild, pains. gastrointestinal, renal and central nervous system.

Technetium 99m-Sestamibi / Iodine123 substraction scanning is the best procedure to locate the enlanged parathyroid glands. ${ }^{6-7}$ But because Technetium
99m-Sestamibi/Iodine-123 Substraction Scanning is not available, we only performed high resolution ultrasound (Color Doppler USG) examination to detect enlargement of parathyroid glands.

In summary, we have reported a girl with hyperparathyroidism caused by single parathyroid adenoma. The diagnosis was delay resulting in pethologic fractures. Removal of theadenoma has resulted in normalization of the laboratory alterations. The patient is now followedup to look out the long-term prognosis.

\section{References}

1. Tsang RC, Venkataraman P. Pediatric parathyroid and vitamin $D$ related disorders, In: Kaplan SA, ed. Clinical pediatric and adolescent endocrinology. WB Saunders, Philadelphia; 1982:346-65.

2. Rappaport D, Ziv Y, Rubin M, Huminer D, Dintsman M. Primary hyperparathy roidism in children. J Pediatr Surg 1986; 21:395-7.

3. Netter FH, Forsham PH. Endocrine system and selected metabolic diseases. The CIBA collection of medical illustrations. Volume 4. CIBA 1965:177-83.

4. Heath III H, Hodgson SF, Kennedy MA. Primary hyperparathyroidism. Incidence, morbidity, and potential economic impact in a community. N Engl I Med 1980;302:189-93.

5. Nolan RB, Hayles AB, Woolner LB. Adeof the parathyroid gland in chilnoma of the parathyraid brief review of dren. Report of 622-7.

6. Hindie E, Melliere D, Simon D, Perlemuter, Galle P. Primary hyperparathy roidism: Is Technetium 99m-Sestamibi/ Iodine-123. Substraction scanning the best procedure to locate the enlarged glands before surgery. $\mathrm{J}$ Clin Endocrinol 
Metabol 1995;80:302-7.

7. Mitchell BK, Kinder BK, Cornelius E, Stewart AF. Primary hyperparathyroid ism: preoperative Incalization using Technetium-Sestamibi scanning. J Clin Endocrinol Metabol 1995;80:7-10. 
Metabol 1995;80:302-7.

7. Mitchell BK, Kinder BK, Cornelius E, Stewart AF. Primary hyperparathyroid ism: preoperative localization using Technetium-Sestamibi scanning. J Clin Endocrinol Metabol 1995;80:7-10. 